ARTIGOS

\title{
A CRISE E O DESEMPENHO ECONÔMICO FINANCEIRO DAS EMPRESAS DA CONSTRUÇÃO CIVIL
}

\section{RESUMO}

O estudo tem como objetivo analisar os reflexos da crise econômica nos indicadores de desempenhos econômicos e financeiros nas empresas de construção civil no Brasil. A pesquisa é considerada aplicada, descritiva, quantitativa e explicativa, com base em levantamento de dados no sistema Economática ${ }^{\circledR}$ no período de 2010 a 2015. A amostra é composta por 17 companhias listadas na BM\&FBovespa. Após a coleta dos dados, foi desenvolvida uma análise econômico-financeira por meio dos indicadores de desempenho. Os resultados mostraram que os indicadores econômicos e financeiros apresentaram variações ao longo do período estudado, sendo 2015 o ano em que as empresas sofreram mais fortemente seus reflexos, principalmente em relação ao aumento do endividamento, impactando no resultado líquido e nas taxas de retorno. Desse modo, foi possível inferir que os indicadores econômicos e financeiros das indústrias de construção civil apresentaram variações relevantes no período em análise.

Palavras-chave: Crise Econômica. Indicadores Econômicos e Financeiros. Empresas de Construção.

Sarah Mesquita Lima sarahmesquitalima@gmail.com Doutoranda em Administração de Empresas pela Universidade de Fortaleza (UNIFOR). Professora e chefe da divisão de gestão tecnológica e inovação da UNIFOR.

Maria Eliete Lima Oliveira telietelima@gmaill.com Graduada em Ciências Contábeis pela Faculdade Metropolitana da Grande Fortaleza (FAMETRO).

Marina de Souza Rodrigues marina.bezerra07@gmail.com Graduada em Ciencias Contábeis pela Faculdade Metropolitana da Grande Fortaleza (FAMETRO).

\section{INTRODUÇÃO}

A crise no setor de construção civil é o reflexo de um cenário da economia brasileira marcado nos últimos anos por deterioração fiscal, incertezas políticas, baixo patamar de confiança, queda na produção, recessão econômica, desemprego elevado e crescente e inflação superior ao teto da meta (CBIC, 2015).

Para Bezerra (2015), um dos motivos que agravou a crise na construção civil foi a implementação do Decreto $n^{\circ}$. 8.412/2015, que dispõe sobre a execução financeira dos órgãos, dos fundos e das entidades do Poder Executivo Federal, principalmente relativo às obras públicas federais, fortemente afetadas pelos cortes no orçamento do Programa de Aceleração do Crescimento (PAC) e do Minha Casa, Minha Vida, todos os fatos aliados à crise financeira nas construtoras, algumas atingidas em cheio pela operação Lava-Jato, que apura desvios de recursos da Petrobrás, além da restrição de crédito e alta dos juros. 
De acordo com a Câmara Brasileira da Indústria de Construção (CBIC), como consequência desses fatores, o Setor de Construção Civil registrou em 2015 uma queda de 7,6\% do seu PIB (Produto Interno Bruto), de acordo com levantamentos do IBGE divulgados em 2016, sendo esta a maior queda dos últimos anos (CBIC, 2015).

Conforme Teixeira e Carvalho (2005), a construção civil ao demandar uma ampla variedade de insumos intermediários ao longo do seu processo produtivo, impulsiona o crescimento econômico dos setores que lhe servem como produtores de bens e serviços, formando, dessa forma, uma extensa e complexa cadeia produtiva.

Gonçalves (2015) explica que, por estar inserida nos segmentos que compõem a indústria de base, a construção civil tem um caráter pró-cíclico, ou seja, vai muito bem quando a economia vai bem e muito mal quando a economia vai mal.

Diante do apresentado, urge destacar a Teoria da Contingência a qual considera que as organizações são sistemas abertos que necessitam de cuidadosa gestão para equilibrar as demandas internas, bem como adaptar-se às circunstâncias externas (BURNS; STALKER, 1961; CHANDLER, 1962).

Diante desse contexto, observa-se que o setor de construção vem atravessando um período conturbado, que provavelmente será refletido em seu desempenho econômico- financeiro.

Teixeira e Amaro (2013) apontam que, embora se reconheça a importância de avaliar os fatores não financeiros e intangíveis ligados às organizações e ao seu sucesso, a avaliação do desempenho financeiro nas entidades com fins lucrativos é uma das perspectivas mais importantes na avaliação do seu desempenho, uma vez que sintetiza o impacto de todas as decisões de gestão na capacidade de criação de valor.

De acordo com Duarte e Lamounier (2007, p. 9), "para que a empresa saiba em que posição se encontra no mercado, é necessária uma análise financeira e econômica que sirva de base de comparação com seu setor de atuação."

Assim, tem-se a seguinte problemática para a presente pesquisa: Quais os reflexos da crise no desempenho econômico-financeiro das empresas de construção civil listadas na BM\&FBovespa?

Desse modo, para responder o referido questionamento, tem-se como objetivo analisar os reflexos da crise nos indicadores econômicos e financeiros das empresas do subsetor da construção civil listadas na BM\&FBovespa.

A opção pelo subsetor de construção civil do segmento de edificações para este estudo, justifica-se por sua importância no cenário econômico brasileiro, pois, segundo a CBIC (2015), a construção civil constitui um importante setor para a economia nacional e é responsável direto pela parcela significativa do PIB. De acordo com Amorim (2015), o setor de construção civil é responsável por cerca de $6,5 \%$ do PIB do país e emprega diretamente, mais de 3 milhões de pessoas.

Duarte e Lamounier (2007) já analisaram a situação econômico-financeira das empresas da construção civil, mas no período de 2003 a 2005, o qual não representa a situação atual da economia do setor.

A relevância deste estudo baseia-se no propósito de analisar os reflexos da crise da construção civil no desempenho econômico-financeiro das empresas, possibilitando dessa forma estabelecer uma melhor performance para o enfrentamento da mesma.

Além dessa seção introdutória, o presente estudo está organizado em mais quatro seções da seguinte forma: a segunda seção aborda a respeito do referencial teórico, a terceira seção da metodologia empregada, a quarta seção versa sobre a análise dos resultados e na quinta seção as considerações finais.

\section{REVISÃO DE LITERATURA}

O presente referencial teórico foi dividido em quatro subseções. Na primeira subseção, expõe-se uma visão geral sobre a Construção Civil no Brasil, em seguida, procurou-se identificar as características das empresas pertencentes ao subsetor da construção civil do segmento de edificações. Na segunda subseção, apresentam-se 
os conceitos e estudos sobre a Teoria Contingencial nas organizações. Na terceira, retrata-se sobre o período e efeitos da crise no mercado brasileiro da construção civil. Por fim, na quarta e última subseção, realizou-se a apresentação e a descrição dos indicadores econômicos e financeiros, que servirão como suporte ao atendimento do objetivo proposto pelo estudo.

\subsection{A CONSTRUÇÃO CIVIL NO BRASIL}

Composta por uma complexa cadeia produtiva, a construção civil abrange diversos setores industriais, como: mineração, siderurgia do aço, metalurgia do alumínio e do cobre, vidro, cerâmica, madeira, plásticos, equipamentos elétricos e mecânicos, fios e cabos e diversos prestadores de serviços, como escritórios de projetos arquitetônicos, serviços de engenharia, empreiteiros etc. (MELLO; AMORIM, 2009). Segundo o Código 45 da Classificação Nacional de Atividades Econômicas (CNAE) do IBGE, as atividades da construção civil são classificadas como as atividades de preparação do terreno, as obras de edificações e de engenharia civil, as instalações de materiais e equipamentos necessários ao funcionamento dos imóveis e às obras de acabamento, contemplando tanto as construções novas, como as grandes reformas, as restaurações de imóveis e a manutenção corrente (OLIVEIRA, 2012).

Conforme o parágrafo primeiro do Artigo 28 da Lei 4.591/64, que dispõe sobre o condomínio em edificações e as incorporações imobiliárias, o objetivo principal das incorporações é o de promover e realizar a construção, para alienação total ou parcial, de edificações, ou conjunto de unidades autônomas (BRASIL, 1964).

De acordo com Trevisan (2010), a construção civil é responsável pela contratação de mão de obra (operários), máquinas, equipamentos e tecnologia construtiva, além de testes de qualidade e ensaios tecnológicos para a realização material do empreendimento; dessa forma, a construtora é a empresa responsável pela execução física do empreendimento.

Diante do apresentado, é importante salientar que o setor da construção civil vem passando por uma fase crítica a qual demanda que a gestão das empresas atuantes no setor se adeque ao ambiente no sentido de neutralizar os efeitos da crise; nesse sentido, urge destacar a Teoria da Contingência.

\subsection{TEORIA DA CONTINGÊNCIA}

A Teoria da Contingência surgiu a partir do resultado de uma série de pesquisas realizadas para verificar os modelos organizacionais mais eficazes em determinados tipos de empresas (FERREIRA; REIS; PEREIRA, 2002).

Ferreira, Reis e Pereira (2002) relatam ainda que, ao comprovar que métodos eficientes em certas situações não surtiam os mesmos resultados, os precursores da teoria contingencial (Joan Woodward, Alfredo Chandler, Tom Burns, G.M. Stalker) tentaram encontrar justificativas para esses resultados divergentes. Após várias pesquisas, concluíram que os resultados eram diferentes porque as situações eram diferentes.

É quando surge o termo "contingencial" baseado no conceito da incerteza de que algo pode ou não ocorrer. A questão passava então a ser qual método aplicar e em quais situações, para obter os melhores resultados possíveis.

De acordo com o visto, salienta-se que a Teoria da Contingência está direcionada prioritariamente para os modelos organizacionais adequados a situações específicas, não existindo, portanto, uma universalidade dos princípios da administração, nem a melhor maneira de organizar e/ou estruturar as organizações.

Para Kwasnicka (2003), a abordagem contingencial tem como principal atributo preparar a organização para uma adaptação rápida por meio da implementação do processo de solução de problemas à medida que uma contingência do ambiente interno ou externo, assim o exige.

Por fim, de acordo com os precursores desta teoria (BURNS; STALKER, 1961; CHANDLER, 1962), ela considera que as organizações são sistemas abertos que necessitam de cuidadosa gestão para equilibrar as demandas internas, bem como adaptar-se às circunstâncias externas. 
Tendo em vista o exposto, importa destacar a trajetória e os efeitos da crise no mercado brasileiro especificamente no setor da construção civil, conforme evidenciado a seguir.

\subsection{A CRISE NO MERCADO BRASI- LEIRO DA CONSTRUÇÃO CIVIL}

O setor da Construção civil vivenciou nos últimos anos duas fases distintas: primeiro, com a economia do país em alta experimentou um forte crescimento e registrou o auge da prosperidade. Porém, com a desaceleração da economia brasileira entrou uma forte retração econômica (UMPIERES, 2016).

A indústria da construção civil possui grande relevância para a economia do País, visto que é um setor amplo e suas atividades relacionam-se de forma direta com a economia, pois é uma grande geradora de emprego, renda e tributos (TEIXEIRA; CARVALHO, 2005).

A CBIC divulgou que, em 2015, a economia brasileira, de acordo com o IBGE, apresentou redução de $3,8 \%$ em seu PIB, a maior registrada na nova série histórica, iniciada em 1996. Considerando a série anterior, o resultado no ano passado foi o pior dos últimos 25 anos. Para a Construção Civil o IBGE registrou em 2015, uma queda de 7,6\% em seu PIB, a maior queda nos últimos anos.

Conforme levantamento feito pela consultoria econômica, a construção civil foi um dos setores que mais sofreu na bolsa de valores nos últimos anos. Após ter atingido seu valor máximo histórico em 14 de outubro de 2010 quando as 16 empresas imobiliárias somaram um valor total de $\mathrm{R} \$ 57,1$ bilhões. O setor teve seu pior momento em 18 de janeiro de 2016 quando teve seu valor de mercado somado de apenas $\mathrm{R} \$ 12,3$ bilhões, o que representou uma queda de $78,43 \%$ ou R $\$ 44,8$ bilhões (UMPIERES, 2016).

Amorim (2015) aponta que, de acordo com a pesquisa de Melhores \& Maiores, a rentabilidade do setor de construção civil caiu de 11,2\% em 2013 para 2,3 em 2014, evidenciando a existência de uma crise sem precedentes no mercado brasileiro de construção civil.
De acordo com Almeida, Novais e Rocha (2016), a retração econômica ocasionou uma redução dos lucros retidos e o aumento do grau de endividamento das empresas não financeiras entre 2010 e 2015 produzindo um cenário em que atesta a incapacidade de retornar o financiamento dos seus investimentos, inviabilizando a retomada do investimento pelo setor privado nacional.

O cenário da economia brasileira, marcado nos últimos anos por deterioração fiscal, incertezas políticas, baixo patamar de confiança, queda na produção, recessão econômica, desemprego elevado e crescente e inflação superior ao teto da meta (estagflação), resultou na desaceleração da economia e mais especificadamente no setor da Construção Civil (CBIC, 2015).

Considerando que o setor de construção civil no Brasil, é altamente dependente de investimentos governamentais para os financiamentos de aquisição da casa própria, um dos motivos que agravou a crise na construção civil foi a implementação do Decreto $n^{\circ}$. 8.412/2015, que dispõe sobre a execução financeira dos órgãos, dos fundos e das entidades do Poder Executivo Federal (BRASIL, 2015), principalmente relativo às obras públicas federais, fortemente afetadas pelos cortes no orçamento do Programa de Aceleração do Crescimento (PAC) e do Minha Casa, Minha Vida, todos os fatos aliados à crise financeira nas construtoras, algumas atingidas em cheio pela operação Lava-Jato, que apura desvios de recursos da Petrobrás, além da restrição de crédito e alta dos juros (BEZERRA, 2015).

Considerando o evidenciado, uma maneira de se avaliar o efeito da crise no setor da construção civil é por meio de indicadores econômicos e financeiros, os quais serão detalhados em seguida.

\subsection{INDICADORES ECONÔMICO-FI- NANCEIROS}

Para se realizar a análise da situação econômica e financeira das entidades é necessário o uso de técnicas de análise das demonstrações contábeis, tradicionalmente efetuado por meio 
da apuração dos indicadores ou quocientes, fornecendo uma ampla visão patrimonial, financeira e econômica das organizações (ASSAF NETO, 2012; SILVA, 2014).

Matarazzo (2008, p. 147) define que "índice é a relação entre contas ou grupo de contas das Demonstrações Financeiras, que visa evidenciar determinado aspecto da situação econômica ou financeira de uma empresa." $\mathrm{O}$ autor define ainda que os índices são divididos conforme seus aspectos, em índices financeiros (índices de estrutura de capitais e índices de liquidez) e econômicos (índice de rentabilidade).

Esse entendimento é compartilhado por Marion (2010) ao destacar que, para se ter condições de conhecer a situação econômico- -financeiro de uma empresa é imprescindível a utilização dos três pontos fundamentais de análise, Liquidez (Situação Financeira), Rentabilidade (Situação Econômica) e Endividamento (Estrutura de Capital).

No entanto, para Silva (2014), Martins, Miranda e Diniz (2014) e Assaf Neto (2012), os índices econômico-financeiros devem ser classificados em quatro grupos, que são: os índices de atividade, índices de liquidez, índices de estrutura de capital ou endividamento e índices de rentabilidade.

Sendo assim, para o presente estudo, optou-se pela utilização dos índices conforme destacados no Quadro 1, no qual apresentam-se as definições dos indicadores que serão objetos desse estudo de acordo com diferentes autores.

\begin{tabular}{|c|c|c|c|c|}
\hline \multirow{2}{*}{$\begin{array}{c}\text { Indica- } \\
\text { dores }\end{array}$} & \multicolumn{4}{|c|}{ Autores } \\
\hline & Matarazzo (2008) & Marion (2010) & Assaf Neto (2012) & Silva (2014) \\
\hline 吾 & $\begin{array}{l}\text { Possibilitam avaliar } \\
\text { os ciclos operacionais } \\
\text { e de caixa da empresa } \\
\text { por meio do estudo da } \\
\text { média de dias em que } \\
\text { a empresa leva para } \\
\text { renovar os estoques, } \\
\text { receber suas vendas e } \\
\text { pagar as compras. } \\
\end{array}$ & $\begin{array}{l}\text { Estudam quantos } \\
\text { dias, em média, uma } \\
\text { empresa leva para } \\
\text { receber suas vendas, } \\
\text { pagar suas compras e } \\
\text { renovar seus estoques. }\end{array}$ & $\begin{array}{l}\text { Permitem que seja } \\
\text { analisado o desem- } \\
\text { penho operacional da } \\
\text { empresa e suas ne- } \\
\text { cessidades de investi- } \\
\text { mento em giro. }\end{array}$ & $\begin{array}{l}\text { Confrontam o es- } \\
\text { paço de tempo para } \\
\text { realizar monetaria- } \\
\text { mente as vendas } \\
\text { com o prazo que } \\
\text { se tem para o paga- } \\
\text { mento aos fornece- } \\
\text { dores. }\end{array}$ \\
\hline$\frac{N}{\mathscr{d}}$ & $\begin{array}{l}\text { Mensuram o quão só- } \\
\text { lida é a base financeira } \\
\text { da empresa. }\end{array}$ & $\begin{array}{l}\text { Avaliam se uma determi- } \\
\text { nada empresa tem capa- } \\
\text { cidade para saldar seus } \\
\text { compromissos, conside- } \\
\text { rando longo prazo, curto } \\
\text { prazo ou imediato. }\end{array}$ & $\begin{array}{l}\text { Demonstram a situa- } \\
\text { ção financeira de uma } \\
\text { empresa frente a seus } \\
\text { diversos compromis- } \\
\text { sos assumidos. }\end{array}$ & $\begin{array}{l}\text { Avaliam o grau de } \\
\text { solvência da em- } \\
\text { presa, ou seja, a ca- } \\
\text { pacidade financei- } \\
\text { ra para saldar seus } \\
\text { compromissos. } \\
\end{array}$ \\
\hline 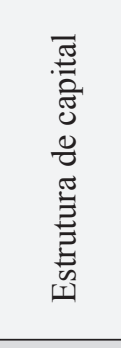 & $\begin{array}{l}\text { Apontam as opções de } \\
\text { decisões financeiras } \\
\text { em termos de obten- } \\
\text { ção e aplicação de re- } \\
\text { cursos. }\end{array}$ & $\begin{array}{l}\text { Responsável por indi- } \\
\text { car se em suas transa- } \\
\text { ções a empresa em sua } \\
\text { maioria, utilizam-se } \\
\text { recursos de terceiros } \\
\text { ou de seus próprios re- } \\
\text { cursos. }\end{array}$ & $\begin{array}{l}\text { Avaliam a proporção } \\
\text { dos recursos próprios } \\
\text { e de terceiros, assim } \\
\text { como a dependência } \\
\text { financeira da empresa } \\
\text { a curto prazo, sua na- } \\
\text { tureza e o risco finan- } \\
\text { ceiro. }\end{array}$ & $\begin{array}{l}\text { Demonstram as de- } \\
\text { cisões financeiras } \\
\text { adotadas pela em- } \\
\text { presa, em termos } \\
\text { de obtenção e apli- } \\
\text { cação de recursos. }\end{array}$ \\
\hline 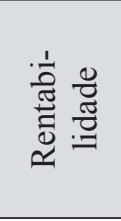 & $\begin{array}{l}\text { Demonstram quanto } \\
\text { renderam os investi- } \\
\text { mentos da empresa. }\end{array}$ & $\begin{array}{l}\text { Avaliam o retorno ob- } \\
\text { tido sobre os investi- } \\
\text { mentos. }\end{array}$ & $\begin{array}{l}\text { Dimensionam o retor- } \\
\text { no sobre os investi- } \\
\text { mentos realizados. }\end{array}$ & $\begin{array}{l}\text { Avaliam o desem- } \\
\text { penho global da } \\
\text { empresa por meio } \\
\text { do estudo das taxas } \\
\text { de retorno. }\end{array}$ \\
\hline
\end{tabular}

Quadro 1 - Indicadores econômico-financeiros adotados.

Fonte: (MATARAZZO, 2008; MARION, 2010; ASSAF NETO, 2012; SILVA, 2014). 


\section{METODOLOGIA}

Diante do objetivo da pesquisa, foi realizado um levantamento de dados no sistema Economática ${ }^{\circledR}$ no período de 2010 a 2015.

$\mathrm{O}$ presente estudo pode ser classificado, de acordo com Gil (2008), quanto à natureza como uma pesquisa aplicada, quanto à forma de abordagem do problema como quantitativa, quanto aos objetivos, descritiva e explicativa, e, por fim, quanto aos procedimentos técnicos como bibliográfica, documental e ex-post-facto.

\subsection{POPULAÇÃO E AMOSTRA}

A população da pesquisa é composta pelas empresas do setor da construção civil listadas na BM\&FBovespa, a amostra é composta por 17 empresas do setor econômico consumo cíclico, subsetor de construção civil do segmento de edificações, conforme o Quadro 2.

\subsection{A COLETA DOS DADOS}

Foram utilizados dados secundários para a elaboração do presente estudo, coletados no banco de dados Economática ${ }^{\circledR}$. Utilizaram-se as informações relacionadas aos indicadores econômico-financeiros supracitados apresentados pelas 17 empresas que compõe a amostra no período de 2010 a 2015.

A escolha deste recorte temporal foi feita em função de Almeida, Novais e Rocha (2016), os quais salientam que a retração econômica ocasionou uma redução dos lucros retidos e o aumento do grau de endividamento das empresas não financeiras entre 2010 e 2015.

\subsection{INDICADORES E VARIÁVEIS OB- SERVADAS}

É possível estabelecer uma tendência da trajetória seguida pelas empresas por meio da

\begin{tabular}{|c|c|}
\hline Razão social & Nome de pregão \\
\hline Construtora Adolpho Lindenberg S.A & Const.A Lind \\
\hline CR 2 Empreendimentos Imobiliários S.A & CR 2 \\
\hline Cyrela Brazil Realty S.A. Empreend. e Part. & Cyrela Realt \\
\hline Direcional Engenharia S.A. & Direcional \\
\hline Even Construtora e Incorporadora S.A. & Even \\
\hline Ez Tec Empreend. E Participações S.A. & Eztec \\
\hline Gafisa S.A. & Gafisa \\
\hline Helbor Empreendimentos S.A. & Helbor \\
\hline JHSF Participações S.A. & JHSF Part \\
\hline João Fortes Engenharia S.A. & João Fortes \\
\hline MRV Engenharia e Participações S.A. & MRV \\
\hline PDG Realt S.A. Emprend. e Participações & PDG Realt \\
\hline Rodobens Negócios Imobiliários S.A. & Rodobens Imob \\
\hline Rossi Residencial S.A. & Rossi Resid \\
\hline Tecnisa S.A. & Tecnisa \\
\hline Trisul S.A. & Trisul \\
\hline Viver Incorporadora e Construtora S.A. & Viver \\
\hline
\end{tabular}

Quadro 2 - Indústrias da Construção Civil do Setor Consumo Cíclico do Segmento de Edificações Fonte: elaboração própria.

Os indicadores econômico-financeiros das empresas listadas no Quadro 2 serão analisados no período entre os anos de 2010 a 2015. comparação de indicadores em um determinado período, revelando diversas características quanto às políticas adotadas pelas empresas ou quanto ao ambiente econômico-financeiro em que aquelas se encontram inseridas (MATA- 
RAZZO, 2003).

Hall, Beck e Toledo Filho (2013) salientam ainda, em consonância com Matarazzo
(2003), que é fundamental a análise conjunta dos índices. Nesse sentido, apresentam-se no Quadro 3 os indicadores-base utilizados no estudo.

\begin{tabular}{|c|c|c|c|c|c|}
\hline \multicolumn{2}{|r|}{ Indicadores } & Fórmula & Indica & Fonte & \begin{tabular}{|c|} 
Inter- \\
pretação
\end{tabular} \\
\hline \multirow{3}{*}{ 营 } & $\begin{array}{l}\text { PMRE (Prazo } \\
\text { médio rotação } \\
\text { dos estoques) }\end{array}$ & $\begin{array}{l}\text { [(Estoque médio/Custos dos } \\
\text { produtos vendidos })] \text { x } 360\end{array}$ & $\begin{array}{l}\text { O tempo médio para re- } \\
\text { novação dos estoques. }\end{array}$ & $\begin{array}{l}\text { Silva } \\
(2014)\end{array}$ & $\begin{array}{l}\text { Quanto } \\
\text { menor, } \\
\text { melhor }\end{array}$ \\
\hline & $\begin{array}{l}\text { PMRV (Prazo } \\
\text { médio rec. das } \\
\text { vendas) } \\
\end{array}$ & $\begin{array}{l}\text { [(Duplicatas a receber (média) / } \\
\text { Receita Líquida de Vendas)]_x } 360\end{array}$ & $\begin{array}{l}\text { O tempo médio espe- } \\
\text { rado para recebimento } \\
\text { das Vendas. }\end{array}$ & $\begin{array}{l}\text { Silva } \\
(2014)\end{array}$ & $\begin{array}{l}\text { Quanto } \\
\text { menor, } \\
\text { melhor }\end{array}$ \\
\hline & $\begin{array}{l}\text { PMPC (Prazo } \\
\text { médio pgto. } \\
\text { das compras) }\end{array}$ & $\begin{array}{l}{[(\text { Fornecedores (média) / }} \\
\text { Compras anuais a prazo })] \text { x } 360\end{array}$ & $\begin{array}{l}\text { O prazo médio para } \\
\text { pagamento aos } \\
\text { fornecedores }\end{array}$ & $\begin{array}{l}\text { Silva } \\
(2014)\end{array}$ & $\begin{array}{l}\text { Quanto } \\
\text { maior, } \\
\text { melhor }\end{array}$ \\
\hline \multirow{3}{*}{ 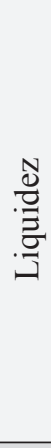 } & Liquidez Geral & $\begin{array}{l}\text { (Ativo Circulante + Realizável a } \\
\text { Longo Prazo) / (Passivo Circulante } \\
\text { + Exigível a Longo Prazo) }\end{array}$ & $\begin{array}{l}\text { Quanto a empresa possui } \\
\text { a receber em relação à } \\
\text { sua dívida total. }\end{array}$ & $\begin{array}{l}\text { Matarazzo } \\
(2008)\end{array}$ & $\begin{array}{l}\text { Quanto } \\
\text { maior, } \\
\text { melhor }\end{array}$ \\
\hline & $\begin{array}{l}\text { Liquidez Cor- } \\
\text { rente }\end{array}$ & $\begin{array}{l}\text { Ativo Circulante / Passivo } \\
\text { Circulante. }\end{array}$ & $\begin{array}{l}\text { Quanto a empresa pos- } \\
\text { sui a receber em curto } \\
\text { prazo em relação a sua } \\
\text { dívida no curto prazo. }\end{array}$ & $\begin{array}{l}\text { Matarazzo } \\
(2008)\end{array}$ & $\begin{array}{l}\text { Quanto } \\
\text { maior, } \\
\text { melhor }\end{array}$ \\
\hline & Liquidez Seca & $\begin{array}{l}\text { (Ativo Circulante - Estoques) / } \\
\text { Passivo Circulante }\end{array}$ & $\begin{array}{l}\text { A disponibilidade de ativos } \\
\text { líquidos em relação a sua } \\
\text { dívida de curto prazo. } \\
\end{array}$ & $\begin{array}{l}\text { Matarazzo } \\
(2008)\end{array}$ & $\begin{array}{l}\text { Quanto } \\
\text { maior, } \\
\text { melhor }\end{array}$ \\
\hline \multirow{3}{*}{ 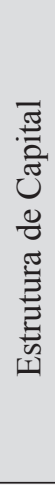 } & $\begin{array}{l}\text { Grau de } \\
\text { endividamento }\end{array}$ & $\begin{array}{l}\text { [(Passivo Circulante + Exigível } \\
\text { em longo prazo) / Patrimônio } \\
\text { Líquido } \text { x } 100\end{array}$ & $\begin{array}{l}\text { A relação de } \\
\text { dependência da empresa } \\
\text { no que se refere ao } \\
\text { capital de terceiros } \\
\end{array}$ & $\begin{array}{l}\text { Silva } \\
(2014)\end{array}$ & $\begin{array}{l}\text { Quanto } \\
\text { menor, } \\
\text { melhor }\end{array}$ \\
\hline & $\begin{array}{l}\text { Composição } \\
\text { do Endivida- } \\
\text { mento }\end{array}$ & $\begin{array}{l}\text { [(Passivo Circulante) /(Passivo } \\
\text { circulante + Exigível a longo } \\
\text { prazo) }] \text { x100 }\end{array}$ & $\begin{array}{l}\text { Indica qual o percen- } \\
\text { tual de obrigações em } \\
\text { curto prazo em relação } \\
\text { ao total de obrigações. }\end{array}$ & $\begin{array}{l}\text { Matarazzo } \\
(2008)\end{array}$ & $\begin{array}{l}\text { Quanto } \\
\text { menor, } \\
\text { melhor. }\end{array}$ \\
\hline & $\begin{array}{l}\text { Imobilização } \\
\text { do Patrimônio } \\
\text { Líquido }\end{array}$ & $\begin{array}{l}\text { [(Investimentos + imobilizados } \\
\text { + intangível) / (Patrimônio } \\
\text { Líquido) }] \text { x } 100\end{array}$ & $\begin{array}{l}\text { Quanto do patrimônio } \\
\text { líquido está aplicado } \\
\text { no Ativo permanente. }\end{array}$ & $\begin{array}{l}\text { Silva } \\
(2014)\end{array}$ & $\begin{array}{l}\text { Quanto } \\
\text { menor, } \\
\text { melhor. }\end{array}$ \\
\hline \multirow{4}{*}{ 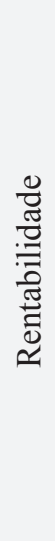 } & Giro do Ativo & Vendas Líquidas / Ativo Total & $\begin{array}{l}\text { O volume de vendas } \\
\text { em relação ao capital } \\
\text { investido total. }\end{array}$ & $\begin{array}{l}\text { Matarazzo } \\
(2008)\end{array}$ & $\begin{array}{l}\text { Quanto } \\
\text { maior, } \\
\text { melhor }\end{array}$ \\
\hline & $\begin{array}{l}\text { Margem } \\
\text { liquida }\end{array}$ & $\begin{array}{l}\text { (Lucro Líquido / Vendas } \\
\text { Líquidas) x } 100\end{array}$ & $\begin{array}{l}\text { O lucro obtido em } \\
\text { relação às vendas. }\end{array}$ & $\begin{array}{l}\text { Matarazzo } \\
(2008)\end{array}$ & $\begin{array}{l}\text { Quanto } \\
\text { maior, } \\
\text { melhor }\end{array}$ \\
\hline & $\begin{array}{l}\text { ROA (Ren- } \\
\text { tabilidade do } \\
\text { Ativo) }\end{array}$ & $\begin{array}{l}\text { (Lucro Líquido/ Ativo Total) x } \\
100\end{array}$ & $\begin{array}{l}\text { O poder de ganho da } \\
\text { empresa. }\end{array}$ & $\begin{array}{l}\text { Marion } \\
(2010)\end{array}$ & $\begin{array}{l}\text { Quanto } \\
\text { maior, } \\
\text { melhor }\end{array}$ \\
\hline & $\begin{array}{l}\text { ROE (Renta- } \\
\text { bilidade PL) }\end{array}$ & $\begin{array}{l}\text { (Lucro Líquido / Patrimônio } \\
\text { Líquido) x } 100\end{array}$ & $\begin{array}{l}\text { Indica o ganho sobre o } \\
\text { capital próprio investido. }\end{array}$ & $\begin{array}{l}\text { Matarazzo } \\
(2008)\end{array}$ & $\begin{array}{l}\text { Quanto } \\
\text { maior, } \\
\text { melhor }\end{array}$ \\
\hline
\end{tabular}

Quadro 3 - Indicadores econômico-financeiros adotados

Fonte: construído a partir de Matarazzo (2008), Marion (2010) e Silva (2014). 
Onde:

- Estoque médio $=($ estoque anterior + estoque atual) / 2

- Duplicatas a receber $($ média $)=($ Duplicatas a receber anterior + Duplicatas a receber atual) / 2

- Fornecedores $($ média $)=($ Fornecedores anterior + Fornecedores atual) $/ 2$

Foram escolhidos apenas os indicadores citados, pois de acordo com Martins, Miranda e Diniz (2014) não há necessidade da utilização de uma grande quantidade de índices para se fazer uma boa análise, pois o mais importante é que sejam utilizados os índices adequados a situação da entidade em análise.

\subsection{TÉCNICAS UTILIZADAS PARA ANÁLISE DOS DADOS}

Os indicadores de atividade, liquidez, estrutura de capital e rentabilidade das 17 empresas que compõe a amostra serão analisados na escala temporal de 2010 a 2015, por meio da média obtida para cada indicador, sendo operacionalizados no Microsoft Excel.

A média temporal será apresentada graficamente, retratando a tendência verificada no setor em análise, no que tange ao comportamento dos indicadores econômicos e financeiros deste setor, no contexto da crise.

Observa-se que foram retirados da análise dos indicadores de estrutura de capital os índices negativos, para evitar viés da análise prejudicando os resultados.

\section{ANÁLISE DE DADOS E RESULTA- DOS}

Inicialmente, conforme a Figura 1, pode-se observar o prazo médio de rotação de estoque (PMRE), prazo médio de recebimento de vendas (PMRV) e prazo médio do pagamento das compras (PMPC). De acordo com os resultados obtidos, nota-se que o PMRE se manteve em ascensão durante os anos de 2010 a 2015.

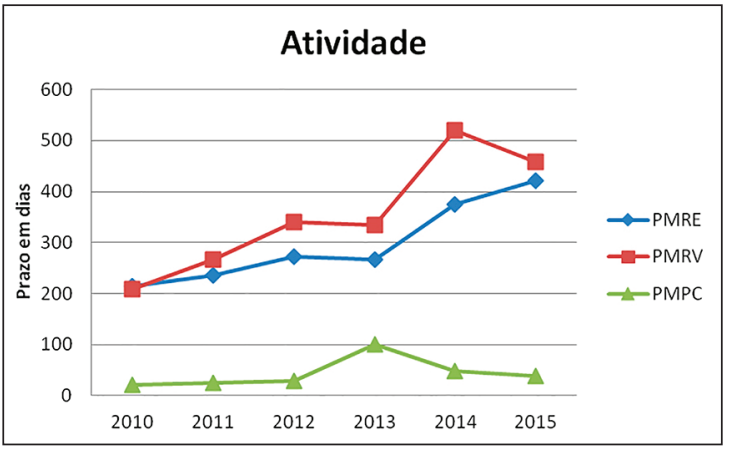

Figura 1 - Indicadores de Atividade Fonte: dados da pesquisa.

Chegando a seu marco no último ano, com aproximadamente 410 dias em média para rotação dos estoques, já o PMRV comportou-se da mesma forma, porém com um declínio em 2015; em contrapartida observa-se que o PMPC durante o período abordado por este estudo sempre se manteve abaixo dos demais. Isso significa que o tempo para pagamento de fornecedores é menor que o do recebimento das vendas.

Observa-se que o tempo para pagamento de compras é menor que o período para recebimento de vendas e o de renovação de estoque, conforme Marion (2010), para que a situação financeira de uma empresa seja considerada ideal, é necessário que o PMRE e o PMRV apresentem um prazo igual ou menor ao PMPC, conclui-se que a situação das empresas abordadas por este estudo está adversa ao ideal.

As diferenças entre o PMRE, PMRV e PMPC justifica-se pelo fato do alto índice de distrato sofrido pelas empresas, além de que, mediante o cenário econômico as mesmas optaram em não renovar seus estoques, investindo assim na venda das unidades já existentes e na liquidação de dívidas com fornecedores.

Assaf Neto (2012) explica que, além do ciclo operacional ser maior, a relação entre clientes e construtoras é longa, pois, em sua maioria, as empresas oferecem uma garantia de no mínimo cinco anos sobre o imóvel residencial.

Conforme estudo realizado por Ribeiro, Brunozi Junior e Paiva (2013), quando o PMRV e PMRE é maior que o PMPC, demonstra que as empresas do setor tendem a buscar mais recur- 
sos de terceiros para financiar suas atividades.

No tocante aos índices de liquidez, observa-se, conforme a Figura 2, que ao longo do período ocorreram pequenas variações, com uma queda em 2014 na liquidez corrente e uma suave ascensão em 2015 em todos os índices.

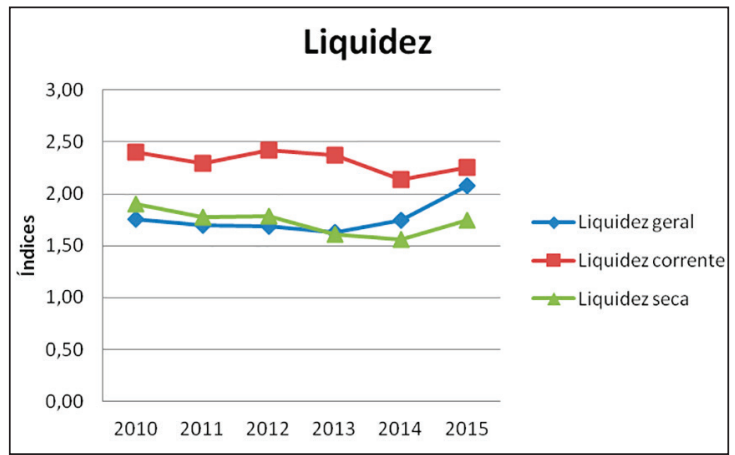

Figura 2 - Indicadores de Liquidez

Fonte: dados da pesquisa.

Verifica-se que durante o período analisado, somente no ano de 2015, os índices obtiveram uma significante elevação, pode-se atribuir tal fato pela intensificação da monetização de ativos, para geração de caixa, garantindo uma media de 1,7 a 2,5 para o periodo, o que segundo Matarazzo (2008) pode-se considerar um bom resultado.

De acordo com Silva (2014), o objetivo principal para o estudo da liquidez é avaliar a capacidade financeira que as empresas têm para saldar seus compromissos.

Conforme Bruni (2011), a tarefa mais desafiadora da gestão financeira de qualquer empresa faz referência à gestão dos recursos líquidos serem capazes de assegurar pagamentos vindouros.

Os bons resultados dos índices de liquidez significam garantia de capacidade de pagamento das dívidas por meio de ativos disponíveis, aponta estudo realizado por Nascimento (2011).

Contudo, em relação ao nível de endividamento e a estrutura de capital das empresas, conforme apresentados na Figura 3, pode-se constatar que durante todo o período analisado houve um aumento do endividamento médio das empresas pesquisadas do segmento de construção civil.

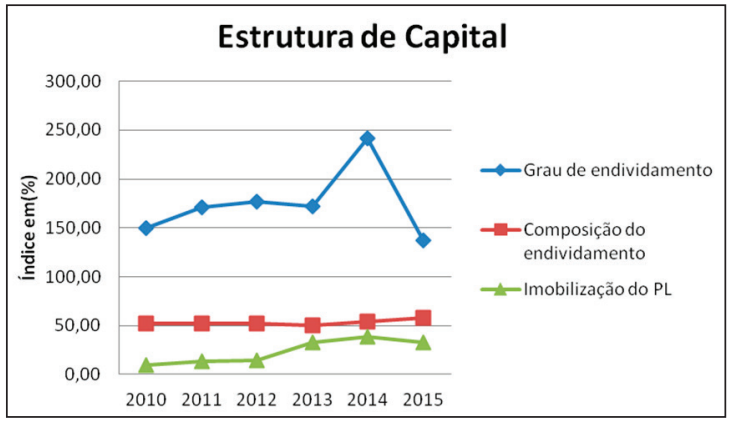

Figura 3 - Indicadores de Estrutura de Capital Fonte: dados da pesquisa.

Pode-se perceber, por meio da análise da Figura 3, que especialmente o grau de endividamento medido pela relação entre capitais de terceiros sobre o patrimônio líquido apresentou acréscimos durante todo o período analisado, tendo seu ponto máximo em 2014, quando a relação da dependência das empresas no que se refere ao capital de terceiros aumentou substancialmente; contudo, em 2015 houve uma redução significativa, porém ainda distante do nível desejado para o momento, devido à alta dos juros.

De acordo com Matarazzo (2003), somente é vantajoso trabalhar com capitais de terceiros quando o custo desse capital é inferior ao lucro líquido gerado com a aplicação desse capital nos negócios; entretanto, de acordo com pesquisa realizada por Ribeiro, Brunozi Junior e Paiva (2013), as empresas do setor de construção civil utilizam-se de capital de terceiros para maior parte de seus financiamentos.

Quanto à composição do endividamento que mensura as dívidas de curto prazo em relação ao endividamento total, é possível visualizar que entre 2010 e 2013 que este indicador teve um crescimento gradativo, tendo aumento mais significativo nos anos de 2014 e 2015, período em que houve maior necessidade de capital de terceiros.

Nesse sentido, Marion (2010) destaca que se a composição do endividamento estiver concentrada no passivo circulante, a empresa poderá ter dificuldades durante uma reversão de mercado, o que lhe proporcionará poucas alternativas durante o enfrentamento de uma crise.

Em relação ao estudo do comportamen- 
to da imobilização do patrimônio líquido, que identifica quanto do patrimônio líquido está sendo aplicado em investimento imobilizado e intangível, pode-se concluir que, no período de 2010 a 2012, registrou-se um leve acréscimo, porém no período entre 2013 a 2015 houve uma elevação significativa deste indicador, proveniente da aquisição de investimento pelas empresas estudadas com seus recursos próprios. Este fato, de acordo com Silva (2014), torna as empresas mais dependentes de capitais de terceiros para seu capital de giro.

$\mathrm{O}$ aumento do endividamento fez que houvesse um acréscimo no custo da dívida por meio dos encargos financeiros, impactando os resultados das empresas como um todo.

Dessa forma, pode-se afirmar que os resultados sofreram fortemente os reflexos da retração econômica vivida nos últimos anos pela economia brasileira, como pode ser visto na Figura 4, que apresenta os indicadores de rentabilidade das empresas de construção civil pesquisadas. Nesse período, esses índices tiveram uma forte queda.

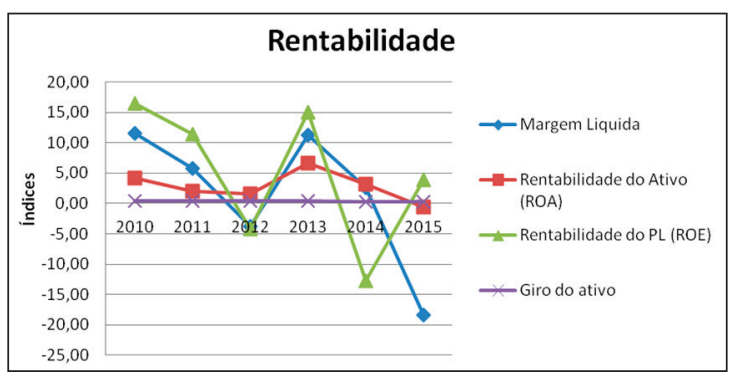

Figura 4 - Indicadores de Rentabilidade

Fonte: dados da pesquisa.

Pode-se observar, por meio da análise da Figura 4, que no período entre 2010 a 2012, com exceção do giro do ativo que permaneceu inerte no período de análise, registrou-se queda em todos os indicadores de rentabilidade. Ressalte-se que todos tiveram um retorno negativo nesse período, isso devido ao prejuízo líquido médio apresentado por esse segmento, a margem líquida e o retorno sobre o patrimônio líquido foram os indicadores que apresentaram maior redução.
Contudo, vale ressaltar que houve uma rápida recuperação em 2013, quando os níveis de rentabilidade ficaram semelhantes a 2010; este fato, de acordo com os relatórios de administração deveu-se à finalização dos projetos e concretização das vendas, aliados à ampla oferta de crédito imobiliário e também à execução de obras preparatórias para Copa do Mundo de 2014.

Entretanto, em 2015, todos os indicadores de rentabilidade, exceto ROE, apresentaram retorno negativo, tendo a margem líquida apresentado a maior queda. Esse resultado ocorreu devido ao prejuízo líquido médio apresentado por esse segmento.

Por fim, vale destacar que esses resultados corroboram o já mencionado por Umpieres (2016) quando salientou que o setor da construção civil teve seu pior momento no início de 2016.

Analisando conjuntamente os indicadores, percebe-se que este estudo, mesmo com resultados indicando o outro extremo, corrobora os resultados de Cavalari, Santos e Rodrigues (2014), os quais, após realizarem uma análise econômica financeira das empresas de capital aberto do setor imobiliário, concluíram que as empresas com maior liquidez e menores níveis de endividamento apresentam maiores níveis de rentabilidade.

Saliente-se ainda que, apesar de o giro do ativo ter permanecido inerte durante o período analisado, deve-se observar que isso não reflete a estabilidade das vendas líquidas, visto que houve uma queda significativa, conforme demonstrado na Figura 5.

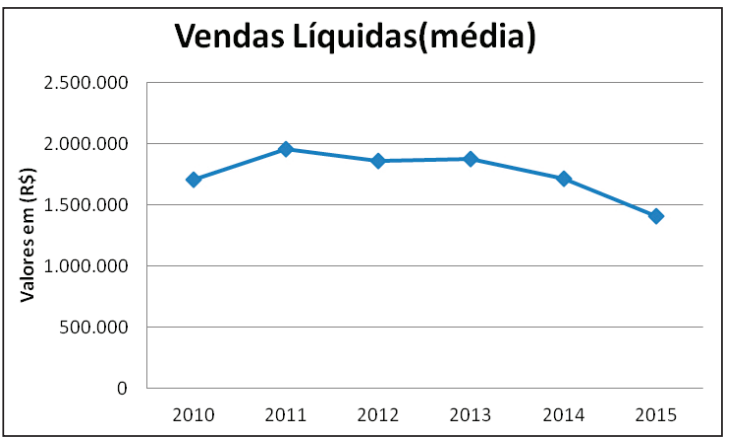

Figura 5 - Vendas Líquidas

Fonte: dados da pesquisa. 
Nota-se, observando a Figura 5, uma redução de forma continuada, praticamente, da média das vendas líquidas do setor desde 2010, apesar de breve elevação no ano de 2011.

Observa-se, no entanto, uma queda nas vendas líquidas no período de 2012 a 2014, apesar das expectativas de ganho em decorrência da realização da Copa do Mundo de 2014 e das Olimpíadas de 2016, os resultados foram frustrantes para a economia do setor.

Em 2015, foi registrada a maior queda nas vendas líquidas do período, o que, de acordo com Amorim (2015), se deu em virtude da expressiva redução no volume de lançamentos e o aumento no nível de distratos ocasionados pela queda no rendimento real das famílias e as restrições na concessão de crédito.

Desse modo, a estabilidade do giro do ativo, a qual é apurada por meio do quociente entre as vendas líquidas e o ativo da entidade, pode ser explicada em virtude de variações no ativo das companhias na mesma proporção da variação das vendas líquidas.

Tal suposição pode ser confirmada, considerando que os relatórios de administração de algumas das empresas analisadas relatam que, para o enfrentamento da crise, visando à redução de passivo e geração de valor para as companhias, foram adotadas medidas estratégicas de contingência como: processo de redução de custos, fortalecimento da estrutura de capital, monetização de ativos e foco na finalização dos projetos já iniciados, em detrimento ao lançamento de novos empreendimentos, o que confirma os preceitos da Teoria da Contingência.

\section{CONSIDERAÇÕES FINAIS}

O estudo objetivou analisar os reflexos da crise econômica vivida nos últimos anos pela economia brasileira nas empresas de construção civil listadas na BM\&FBovespa. Para tanto, fez-se uma análise por meio de indicadores econômicos e financeiros de uma amostra de 17 empresas com base nas demonstrações contábeis coletados no banco de dados Economática ${ }^{\circledR}$, no período de 2010 a 2015.
De um modo geral, pode-se concluir que os indicadores econômicos e financeiros apresentaram variações ao longo do período estudado e revelam que, ainda que a crise venha se arrastando por vários anos, foi no ano de 2015 que as empresas sofreram mais fortemente seus reflexos, principalmente em relação ao aumento do endividamento e ao consequente aumento do custo da dívida impactando o resultado líquido e as taxas de retorno, corroborando com Umpieres (2016).

Saliente-se ainda que se observou que as companhias, como forma de equalizar os efeitos da crise, adotaram medidas estratégicas reforçando os preceitos da Teoria da Contingência.

O estudo limitou-se a analisar as empresas listadas na BM\&FBovespa e, por esse motivo, a análise não pode ser aplicada a todo o subsetor de construção civil. Além do que, não foi realizada uma análise individualizada de cada empresa da amostra, utilizando-se apenas os valores médios dos indicadores. Algumas empresas podem ter sentido menos os reflexos da crise do que outras. Contudo, esse não era o objetivo do estudo.

Vale destacar que, embora o setor da construção civil tenha sofrido com as ações da Lava Jato, nenhuma das empresas em análise está diretamente envolvida com a ação da Polícia Federal; portanto, os resultados encontrados não têm relação direta com a referida ação.

Por fim, salienta-se a contribuição para a ampliação do conhecimento do assunto e sugere-se que a análise seja ampliada para uma avaliação das demais empresas atuantes na construção civil, no sentido de observar se outros fatores influenciaram nos indicadores daquelas.

\section{THE CRISIS AND THE FINANCIAL AND ECONOMIC PERFOMANCE OF CONSTRUCTION COMPANIES}

\section{ABSTRACT}

This study aims at analyzing the effects of the economic crisis of the past few years on financial and economic indexes of civil con- 
struction companies in Brazil. This is considered an applied, descriptive, quantitative and explanatory research based on data collected on Economática ${ }^{\circledR}$ from 2010 to 2015. The sample is composed of 17 companies listed in BM\&FBovespa. After collecting the data, an economic-financial analysis was developed by means of performance indexes. Results showed that the indexes presented variations during the aforementioned period and that 2015 was the year in which the companies suffered the most from the effects of the economic crisis, especially regarding the increase of indebtedness and, consequently, the rise in the cost of debt with an impact on net income and return rates. Thus, it is possible to infer that the economic and financial indexes of civil construction companies presented significant variations in the period analyzed.

Keywords: Economic Crisis. Economic and Financial indexes. Construction Companies.

\section{LA CRISIS Y EL DESEMPEÑO ECONÓMICO E FINANCIERO DE LAS EMPRESAS DE LA CONSTRUCCIÓN CIVIL}

\section{RESUMEN}

El estudio tiene como objetivo analizar los reflejos de la crisis económica de los últimos años en las empresas de construcción civil en Brasil. La investigación es considerada aplicada, descriptiva, cuantitativa y explicativa, con base en levantamiento de datos en el sistema Economática ${ }^{\circledR}$ en el periodo de 2010 a 2015. La muestra es formada por 15 compañías listadas en MB\&FBovespa. Después de colectados los datos, se hizo un análisis económico-financiero por medio de indicadores de desempeño. Los resultados mostraron que los indicadores económicos y financieros presentaron variaciones al largo del periodo bajo estudio, siendo 2015 el año en que las empresas sufrieron de manera más fuerte sus reflejos, principalmente en relación al aumento del endeudamiento, impactando en el resultado líquido y en las tasas del retorno. Así, fue posible inferir que los indicadores económicos y financieros de las empresas de construcción civil presentaron variaciones relevantes en el periodo bajo análisis.

Palabras-clave: Crisis económica. Indicadores económicos y financieros. Empresas de construcción.

\section{LA CRISE ET LES RESULTATS ECONOMIQUES ET FINANCERS DES ENTREPRISES DE LA CONSTRUCTION CIVILE}

\section{RESUME}

L'étude a pour objectif d'analyser les reflets de la crise économique des années récentes sur les indicateurs de résultats économiques et financiers des entreprises de la construction civile au Brésil. La recherche est considérée comme étant appliquée, descriptive, quantitative et explicative, ayant pour base des des données recuperées dans le système Economática ${ }^{\circledR}$ dans la période de 2010 a 2015. L'échantillon est composé de 17 compagnies listées dans BM\&Fbovespa. Après la collection des données, une analyse économique et financière fût développée à travers des indicateurs de résultats. Les conclusions démontrent que les indicateurs économiques et financiers ont présenté des variations pendant la période sous études et que 2015 a été l'année pendant laquelle les entreprises ont souffert plus fortement leurs reflets, fondamentalement en relation à l'augmentation de l'endettement, impactant le résultat liquide et les taux de retour. Ainsi, il nous fût possible déduire que les indicateurs économiques et financiers des compagnies de la construction civile ont présenté des variations considerables dans la période en étude.

Mots-clés: Crise Economique. Indicateurs Economiques et Financiers. Entreprise de la Construction. 


\section{REFERÊNCIAS}

ALMEIDA, Sergio Gomes de; NOVAIS, Luis Fernando; ROCHA, MarcoAntonio.AFragilidade financeira das empresas não financeira no Brasil pós crise. Texto para discussão Unicamp, Campinas, n. 281, p. 1-45, set. 2016.

AMORIM, Lucas. Construção civil vive crise sem precedentes no Brasil. Exame.com, 16 jul. 2015. Disponível em: <http://exame.abril.com. br/revista-exame/a-crise-e-a-crise-da-construcao/>. Acesso em: 5 dez. 2016.

ASSAF NETO, Alexandre. Estrutura e análise de balanços. 10. ed. São Paulo: Atlas, 2012.

BEZERRA, Sandra. Emprego desaba na construção: crise nos canteiros, CBIC Câmara Brasileira da Indústria da Construção. 2015. Disponível em: $<$ http://www.cbic.org.br $>$. Acesso em: 17 nov. 2016.

BRASIL. Decreto Lei ${ }^{\circ} 8.412$, de 26 de fevereiro de 2015. Dispõe sobre a execução financeira dos órgãos, dos fundos e das entidades do Poder Executivo Federal até o estabelecimento do cronograma de que trata o caput do art. $8^{\circ}$ da Lei Complementar $\mathrm{n}^{\circ} 101$, de 4 de maio de 2000, e dá outras providências. Diário Oficial da União, Brasília, DF, 26 fev. 2015.

Lei $n^{0} 4.591$, de 16 de dezembro de 1964. Dispõe sobre o condomínio em edificações e as incorporações imobiliárias. Diário Oficial da União, Brasília, DF, 16 dez.1964.

BRUNI, Adriano Leal. A análise contábil e financeira. 2. ed. São Paulo: Atlas, 2011.

BURNS, T.; STALKER, G. M. The management of innovation. Londres: Tavistock, 1961.

CÂMARA BRASILEIRA DA INDÚSTRIA DA CONSTRUÇÃO - CBIC. PIB 2015. Disponível em: $<$ http://www.cbicdados.com.br/menu/ home/pib-2015>. Acesso em: 1 dez. 2016.
CAVALARI, Vinicius Espúrio; SANTOS, David Ferreira Lopes; RODRIGUES, Santiago Valcacer. Análise econômica e financeira das empresas de capital aberto do setor imobiliário. In: CONGRESSO NACIONAL DE EXCELÊNCIA EM GESTÃO, 10., 2014, Rio de Janeiro. Anais... Rio de Janeiro: Escola de Engenharia da Universidade Federal Fluminense, 2014.. Disponível em: <http://www.inovarse. org/sites/default/files/T14_0096_0.pdf > . Acesso em: 15 dez. 2016.

CHANDLER, A. D. Strategy and structure: history of the industrial enterprise. Massachusetts: The M.I.T. Press, 1962.

DUARTE, H.C.F.; LAMOUNIER, W. M. Análise financeira de empresas da construção civil por comparação com índices-padrão. Enfoque:reflexão Contábil, Minas Gerais, v. 26, n. 2, p. 9-28, 2007.

FERREIRA, Antonio Ademir; REIS, Ana Carla Fonseca; PEREIRA, Maria Isabel. Gestão empresarial: de Taylor aos nossos dias: evolução e tendências da moderna administração de empresas. São Paulo: Pioneira Thomson Learning, 2002.

GIL, Antônio Carlos. Métodos e técnicas de pesquisa social. 6. ed. São Paulo: Atlas, 2008.

GONÇALVES, Robson. Ciclo e tendência na construção civil. 2015. Disponível em: <http:// fgvprojetos.fgv.br/artigos/ciclo-e-tendencia-na-construcao-civil>. Acesso em: 4 mar. 2017.

HALL, Rosemar Jose; BECK, Franciele; TOLEDO FILHO, Jorge Ribeiro de. Análise do impacto da crise subprime nas empresas do agronegócio brasileiro listadas na BM\&F Bovespa. 2012. Custos e agronegócio, Blumenau, v. 9, n. 1, jan./mar. 2013. Disponível em: <www.custosagronegocioonline.com.br>. Acesso em: 25 nov. 2016.

INSTITUTO BRASILEIRO DE GEOGRAFIA 
E ESTATÍSTICA. Site. Disponível em: $<$ https://www.ibge.gov.br/>. Acesso em: 1 dez. 2016.

KWASNICKA, Eunice Lacava. Teoria geral da administração: uma síntese. 3. ed. São Paulo: Atlas, 2003.

MARION, Jose Carlos. Analise das demonstrações contábeis: contabilidade empresarial. 6. ed. São Paulo: Atlas, 2010.

MARTINS, Eliseu; MIRANDA, Gilberto José; DINIZ; Josedilton Alves. Análise didática das demonstrações contábeis. 3. ed. São Paulo: Atlas, 2014.

MATARAZZO, D. C. Análise financeira de balanços: abordagem básica e gerencial. 6 . ed. São Paulo: Atlas, 2003.

MATARAZZO, Dante Carmine. Análise financeira de balanços: abordagem básica e gerencial. 6. ed. São Paulo: Atlas, 2008.

MELLO, S. C. B. B.; AMORIM, S. R. L. O subsetor de edificações da construção civil no Brasil: uma análise comparativa em relação à União Européia e aos Estados Unidos. Produção, São Paulo, v. 19, n. 2, p. 388-399, maio/ ago. 2009. Disponível em: $<$ http://www.scielo.br/pdf/prod/v19n2/v19n2a13.pdf>. Acesso em: 4 mar. 2017.

NASCIMENTO, João Paulo de Brito. Avaliação do desempenho econômico-financeiro das empresas do setor de construção civil: um estudo por meio da analise envoltória de dados. 2011.173 f. Dissertação (Mestrado em Administração) - Universidade Federal de Lavras, Lavras, 2015. Disponível em: <http://repositorio.ufla.br/jspui/handle/1/5152>. Acesso em:13 maio 2017.

OLIVEIRA, Valéria Faria. O papel da indústria da construção civil na organização do espaço e do desenvolvimento regional. In: CONGRES-
SO INTERNACIONAL DE COOPERAÇÃO, 4., 2012, São Paulo. Anais... São Paulo: Universidade-Indústria, 2012.

RIBEIRO, Lucas; BRUNOZI JUNIOR; Antônio Carlos; PAIVA, André Luiz de. Análise multivariada dos indicadores econômicos-financeiros das empresas de construção e engenharia listadas na B\&MFBovespa: um estudo de aplicabilidade da Pecking order theory. In: SIMPÓSIO DE EXCELENCIA EM GESTÃO E TECNOLOGIA, 10., 2013, Resende. Anais... Resende, 2013. Disponível em <http://www. aedb.br/seget/arquivos/artigos 13/49018560. pdf $>$. Acesso em: 13 maio 2017.

SILVA, Alexandre Alcântara da. Estrutura, análise e interpretação das demonstrações contábeis. 4. ed. São Paulo: Atlas, 2014.

TEIXEIRA, Nuno Miguel Delicato; AMARO, Antônio Gerson Cabral. Avaliação do desempenho financeiro e da criação de valor-um estudo de caso. Revista Universo Contábil, Santa Catarina, v. 9, n. 4, p. 157-178, 2013. Disponível em: <http://proxy.furb.br/ojs/index.php/ universocontabil/article/view/3535>. Acesso em: 5 jan. 2017.

TEIXEIRA, Luciene Pires; CARVALHO, Fátima Marília Andrade de. A construção como instrumento do desenvolvimento da economia brasileira. Revista Paraense de Desenvolvimento, Curitiba, n. 109, p. 9-26, jul./dez. 2005. Disponível em: <.file://C:/Users/meus/Desktop/Constru $\% \mathrm{C} 3 \% \mathrm{~A} 7 \% \mathrm{C} 3 \% \mathrm{~A} 3 \mathrm{o} \% 20 \mathrm{civil} / \mathrm{Re}-$ latorios\%20adm/138-471-1-PB.pdf>. Acesso em: 5 dez. 2016.

TREVISAN, Ricardo. A diferença entre construtora e incorporadora.2010. Disponível em: $<$ https://ricardotrevisan.com/2010/07/31/a-diferenca-entre-construtora-e-incorporadora/ $>$. Acesso em: 19 fev. 2017.

UMPIERES, Rodrigo Tolotti. Bolha sem fim: imobiliárias perdem $72 \%$ de valor de mercado 
desde o auge do setor. 2016. Disponível em: $<$ http://www.infomoney.com.br/mercados/acoes-e-índices/noticia/5930569/bolha-sem-fim-imobiliarias-perdem-valor-mercado-desde-auge-setor>. Acesso em: 5 mar. 2017. 